\title{
Can Dental Anxiety During Impacted Third Molar Surgery Be Measured Biometrically? Clinical Study with the Galvanic Skin Response Technique Gömülü Üçüncü Molar Ameliyatı Sırasında Dental Anksiyete Biyometrik Ỏlarak Ölçülebilir mi? Galvanik Deri Yanıtı Tekniği ile Klinik Çalışma \\ (1) Hasan Onur Şimşek ${ }^{1}$, (1) Behiç Alp Aytekin²
}

1Aydın Adnan Menderes University Faculty of Dentistry, Department of Oral and Maxillofacial Surgery, Aydın, Turkey
${ }^{2}$ Aydın Adnan Menderes University Faculty of Communication, Department of Visual Communication Design, Aydın, Turkey

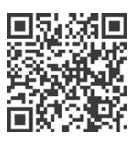

Keywords

Biometric Data, Dental anxiety, galvanic skin response, patient experience, third molar surgery, electrodermal activity

Anahtar Kelimeler

Biyometrik veri, dental anksiyete, galvanik deri yanıtı, hasta deneyimi, üçüncü molar cerrahi, elektrodermal aktivite

Received/Geliş Tarihi : 15.12 .2020

Accepted/Kabul Tarihi : 01.01.2021

doi:10.4274/meandros.galenos.2021.53386

Address for Correspondence/Yazışma Adresi: Hasan Onur Şimşek DDs, PhD,

Aydın Adnan Menderes University Faculty of Dentistry, Department of Oral and Maxillofacial Surgery, Aydın, Turkey

Phone : +902562136347

E-mail : hasanonursimsek@gmail.com

ORCID ID: orcid.org/0000-0001-9628-3014

(C) Meandros Medical and Dental Journal, Published by Galenos Publishing House.

This is article distributed under the terms of the

Creative Commons Attribution NonCommercial 4.0

International Licence (CC BY-NC 4.0).

\begin{abstract}
Objective: The present study aimed to define the experience and stages of dental anxiety in oral and maxillofacial surgery patients using real-time biometric data collection tools.

Materials and Methods: In this study, the patient-dentist interaction was divided into three sessions: The pre-surgery, oral surgery and post-surgery sessions. A software algorithm was used to record the galvanic skin response signals and heart rate data of patients when they sat on the dental chair for a tooth extraction procedure.

Results: A total of 38 patients with a mean age of 24.8 years were included in the study. Fifteen of the participants were men (39.5\%) and 23 were women (60.5\%). In the operative phase, which is the second of the three oral surgery phases, there was a statistically significant difference between the mean values of the op galvanic skin response and op heart rate $(p<0.001)$.

Conclusion: Emotional/motivational changes during the oral surgery stages can be determined through biometric data analysis. The measurement of biometric parameters, combined with the dentist's experience, can enable the dentist to make decisions about preferable procedures and approaches in the treatment of patients with dental anxiety.
\end{abstract}

Öz

Amaç: Bu çalışmanın amacı, gerçek zamanlı biyometrik veri toplama araçlarını kullanarak ağız, diş ve çene cerrahisi hastaların, dental anksiyete deneyimi ve aşamalarını tanımlamaktır.

Gereç ve Yöntemler: Çalışma protokolü ameliyat öncesi, ameliyat ve ameliyat sonrası olmak üzere üç bölüme ayrıldı. Hastaların diş çekimi prosedürü sırasında galvanik deri tepki sinyallerini ve kalp atış hızı verilerini kaydetmek için bir yazılım algoritması kullanıldı. 
Bulgular: Çalışmaya ortalama yaşı 24,8 yıl olan 38 hasta dahil edildi. Katılımcıların 15'i erkek $(\% 39,5), 23$ 'ü kadındı $(\% 60,5)$. Çalışmanın ameliyat bölümü operasyon fazında galvanik deri yanıtı ve kalp atış hızı ortalama değerleri arasında istatistiksel olarak anlamlı fark vardı $(p<0,001)$.

Sonuç: Ağız cerrahisinin aşamalarındaki duygusal/motivasyonel değişiklikler biyometrik veri analizi ile belirlenebilir. Diş hekiminin deneyimi ile birlikte biyometrik parametrelerin ölçümü, diş hekiminin, diş anksiyetesi olan hastaların tedavisinde tercih edilen prosedürler ve yaklaşımlar hakkında kararlar almasını sağlayabilir.

\section{Introduction}

Dental anxiety is an emotional state during which various emotional/motivational changes (concern, fear, stress, and/or excitement) are observed. The effects of this anxiety can impact both the patient and the dentist. The majority of patients experience significant general stress due to previous experiences or environmental factors. Patients with severe anxiety cannot usually suppress their fear, and their emotional reactions, such as vomiting, crying, screaming, etc., may interfere with the surgical intervention. Therefore, general anaesthesia and/or sedation may be necessary. A detailed examination of the patient and the selection of an appropriate approach may help prevent the use of general anaesthesia and sedation; that is, it may allow for the intervention to be conducted under routine clinical conditions. Unnecessary and high-risk procedures are thus avoided, and an atmosphere of mutual trust is established between patient and dentist (1-4).

Electrodermal activity (EDA) known as galvanic skin response (GSR) enables the measurement of unconscious behaviours that cannot be voluntarily controlled. The skin is the largest organ of the body, and it reacts to all cognitive and emotional stimuli through an unconscious system controlled by the autonomous sympathetic nervous system. These reactions can be observed through changes in skin conductance, making the GSR technique an ideal biometric data collection tool for the investigation of emotional/motivational changes (5).

Compared to studies in the literature that are generally focused on the causes of anxiety, this study has a unique mixed-method design and interdisciplinary approach. The biometric recording of patients' anxiety characteristics and the comparison of the results with other reliable and validated anxiety scales are distinctive features of this study. In addition, this study represents a comprehensive attempt to improve data reliability through correct interpretation of the objective numeric data obtained from the interventions and the detailed interviews carried out after the interventions. The objective numeric assessment of the predictive data can contribute to developing a suitable dental treatment approach for patients with dental anxiety.

In this study, the following questions were explored:

- Can surgery for impacted tooth be considered as having different anxiety stages? Which stages specifically (pre-surgery session, oral surgery session, or post-surgery session) have an effect on patients' anxiety level?

- Are the results of dental anxiety scales (DAS) consistent for every patient in the clinical practice?

- Does the patient-dentist interaction affect the anxiety of the patient during surgery?

The main objective of this study is to determine and define the experience and stages of dental anxiety for oral and maxillofacial surgery patients, using realtime biometric data tools. In addition, this study addresses appropriate management of the patientdentist interaction.

\section{Materials and Methods}

The study sample consisted of patients who were older than 18 years, had no systemic disorders, were not under psychiatric treatment and had applied to the Department of Oral and Maxillofacial Surgery in the Faculty of Dentistry at Aydın Adnan Menderes University. Patients who received medical treatment and who had a local pathological condition at the site of the impacted tooth were excluded from the study. The study group was limited to optimise the surgical conditions and to standardise the interventions for the biometric analysis of patients' dental anxiety levels. We included patients who had impacted teeth with vertical and mucosal retention in the mandible according to the Pell-Gregory classification. All patients were informed about the objective of the study and the details of the intervention, and 
only patients who had given their written consent were included in the study. This study followed the Declaration of Helsinki regarding medical protocol and ethics, and the regional Ethical Review Board of Aydın Adnan Menderes University Faculty of Dentistry, approved the study (protocol no: ADÜDHF 2019/066, date: 17.04.2019).

In this study, patient-dentist interaction was divided into three sessions: the pre-surgery session, the oral surgery session, and the post-surgery session. The study procedures are shown in detail in Table 1. In this study, our approach was interdisciplinary and involved of the perspectives of both dentistry and communication sciences.

\section{Pre-surgery Session}

The pre-surgery session refers to the period before the patient was taken into the operating room. In this period, the first interview with the patient and the Modified Dental Anxiety scale (MDAS) survey were conducted. Also, participatory action research (PAR) was started to determine the overall anxiety level of the patient.

\section{Oral Surgery Session}

All surgical interventions were carried out in a single-unit treatment room with standardised illumination, and patients were situated in the room individually. The patients were isolated from stimuli except for the surgical intervention so that only the anxiety related to the surgical stages could be examined. The surgical intervention was divided into three phases: the pre-operative phase (pre-op), the operative phase (op) and the post-operative phase (post-op). As shown in Table 1, each phase was divided into subphases. Biometric data was collected using GSR in all subphases of the oral surgery session, while observation was carried out with PAR at the same time.

\section{Post-surgery Session}

The post-surgery session refers to the period following the surgical intervention, when the embedded third molar tooth extraction was completed. In this session, the state-trait anxiety inventory (STAI) was administered to determine the patient's anxiety status; in addition, a general analysis of the patient's anxiety status using PAR and an indepth interview were conducted, and a cross-check of the STAI was carried out.

\section{Modified Dental Anxiety Scale}

The DAS, which was developed by Corah (6), is one of the oldest and most frequently used scales to measure dental anxiety. Humphris et al. (7) improved certain deficiencies of the DAS and developed the MDAS. The validity and reliability of the Turkish version of this modified scale, which enables a more accurate assessment of dental anxiety, was established (8). MDAS uses a 5-point Likert scale (1= not anxious, $2=$ slightly anxious, $3=$ fairly anxious, $4=$ very anxious, and $5=$ extremely anxious), the total score is between 5 and 25 points.

\section{State-trait Anxiety Inventory}

The (STAI-I, STAI-II) was developed by Spielberg et al. (9). Öner and Le Compte (10) adapted it to the

\begin{tabular}{|c|c|c|c|c|}
\hline \multirow{2}{*}{$\begin{array}{l}\text { Pre-surgery } \\
\text { session }\end{array}$} & \multicolumn{3}{|c|}{ Oral surgery session } & \multirow{2}{*}{$\begin{array}{l}\text { Post-surgery } \\
\text { session }\end{array}$} \\
\hline & Pre-operative phase & Operative phase & Post-operative phase & \\
\hline $\begin{array}{l}\text { Modified Dental } \\
\text { Anxiety scale }\end{array}$ & $\begin{array}{l}\text { P1. Unit preparation } \\
\text { P2. Surgical field } \\
\text { preparation } \\
\text { P3. Surgeon preparation }\end{array}$ & $\begin{array}{l}\text { P4. Local anaesthesia } \\
\text { P5. Waiting anaesthesia } \\
\text { P6. Incision } \\
\text { P7. Tooth extraction } \\
\text { P8. Bleeding control } \\
\text { P9. Suturation } \\
\text { P10. End of extraction }\end{array}$ & $\begin{array}{l}\text { P11. Surgery information } \\
\text { P12. Post-operative information } \\
\text { P13. End of surgery }\end{array}$ & $\begin{array}{l}\text { State and trait } \\
\text { anxiety inventory }\end{array}$ \\
\hline- & $\begin{array}{l}\text { Galvanic skin response } \\
(\mathrm{SCL}) \\
\& \\
\text { Heart rate (HR-bpm) }\end{array}$ & $\begin{array}{l}\text { Galvanic skin response } \\
\text { (SCL) } \\
\& \\
\text { (HR-bpm) }\end{array}$ & $\begin{array}{l}\text { Galvanic skin response } \\
\text { (SCL) } \\
\& \\
\text { (HR-bpm) }\end{array}$ & - \\
\hline \multirow{2}{*}{ PAR } & \multirow{2}{*}{ PAR } & \multirow{2}{*}{ PAR } & \multirow{2}{*}{ PAR } & PAR \\
\hline & & & & In-depth interview \\
\hline
\end{tabular}


Turkish language and conducted reliability and validity tests for the Turkish version. This inventory has two 20 -item scales. The anxiety state scale has a 4-point Likert scale, in which $1=$ not at all, $2=$ somewhat, $3=$ moderately so and $4=$ very much so. The trait anxiety scale is also based on a 4-point Likert scale that assesses the frequency of impressions, thoughts and behaviours, in which 1= almost never, 2 = sometimes, $3=$ often and 4= almost always $(11,12)$.

\section{Galvanic Skin Response}

The GSR device, which measures EDA, was designed for maximum patient comfort. It has only a few connection electrodes and can be easily be applied to patients to collect biometric data. Data were recorded with a Shimmer GSR+ device and analysed simultaneously with the Consensys PRO 1.5.0 software package (13). The Shimmer GSR+ equipment has three channels generating simultaneous feedback. Two of these channels record electrodermal skin conductance level ( $\mathrm{SCL}$ ) signals through the hand electrodes connected to the first and middle fingers, and the third channel collects cardiac volume data from an infrared sensor attached to the left earlobe and converts this data into heart rate (HR) data with the help of a software algorithm. We began recording the SCL of patients, which reveals changes in patients' emotions, as soon as they sat in the dental chair for the tooth extraction procedure (Figure 1).

"Motivational" is the adjective used in the GSR literature to refer to a patient's emotional state (anxiety, fear, excitement, concern, etc.). A change of emotion is described as a change of motivational

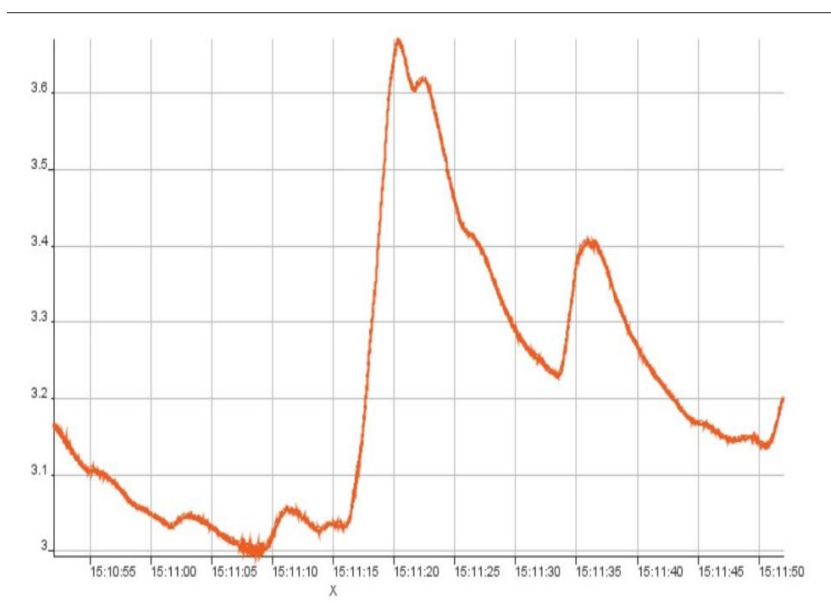

Figure 1. Galvanic skin response skin conductance response measurement of a patient during the oral surgery status. Change is measured by an electrodermal data collection method. The MDAS and the STAI are also administered to identify a change in anxiety state, comprising a mixed method approach. Thus, as can be seen in the research, it is possible to identify in which stages a patient's emotional/motivational state variable changes to anxiety.

\section{In-depth Interview}

According to the mixed-method research design, both quantitative and qualitative data were obtained from the participants. Observation and in-depth interview techniques were implemented to collect the qualitative data. Observation is not only a fundamental data collection method within traditional field research but is also one of the key elements of user research in the context of human-computer interaction. On the other hand, in-depth interviews are based on mutual verbal communication, during which the investigator can create a conversational atmosphere using predetermined topic areas to obtain in-depth information about the behaviours, opinions, emotions and beliefs of participants (14). This method was used as an additional tool to differentiate anxiety from other moods. In our study, in-depth interviews were carried out in the post-surgical session to support the detection of the patient's anxiety status using GSR. Through in-depth interviews, it is also possible to find and clarify which emotional changes in the patient's status of surgical operations correspond to.

\section{Participatory Action Research}

PAR is a technique in which the researcher is involved in the field as a participant, plays an active role in the actions of the research and conducts processes in the name of observing the data. In this method, it is possible to adapt the researcher to the field with multiple roles (15). This method was first coined action research by Lewin (16) (1951). In this method, the investigator can play more than one role in the research field. In our study, the dentist who performed the surgical operation was also a participant observation researcher. In addition to performing the embedded tooth operation, the dentist monitored the patient's GSR data and observed the patient's general emotional/motivational status. The other researcher checked and recorded the GSR data and supervised the flow of the mixed-method approach, observing the condition of the patient and the procedure carried out by the dentist. 


\section{Statistical Analysis}

The G-Power v3.1.9.2 software package was used to calculate the sample size. Relevant studies in the literature were explored, and we referred to the study conducted by Najafpour et al. (17), which was similar to our study. The effect size, which was obtained with the study data, was too high (0.905), so we referred to an effect size of 0.50 ; consequently, the sample size was calculated to be 38 . The type 1 error rate was set to 0.05 , and the power of the study was set to 0.95 by G-Power analysis. The Lilliefors-corrected Kolmogorov-Smirnov test was used for the normal distribution analysis. As some data were not normally distributed, we used non-parametric tests for the analysis. We used the Spearman's correlation test to determine the direction and degree of the relationship between the variables and the Friedman test (twoway analysis of variance by ranks) to investigate the differences between the pre-op, op and post-op data. The Bonferroni test was used as a post-hoc test for multiple comparisons according to the results of the Friedman test. The chi-square test was used to compare patients' anxiety levels before and after the oral surgery. The two-way repeated-measures ANOVA was used to analyse the effect of variables such as age, gender, duration, MDAS and STAI on SCL and pulse values. Considering the ANOVA results, the Bonferroni test was used to perform paired comparisons.

\section{Results}

A total of 38 patients were included in the study with a mean age of 24.8 years (18-39 years). Fifteen were men (39.5\%), and 23 were women (60.5\%). According to the STAI, 10 participants (26\%) experienced a high level of trait anxiety and 10 participants (26\%) experienced a moderate level of trait anxiety, while 18 participants (48\%) had no or only mild anxiety. Regarding patients' STAI scores for state anxiety, 27 participants (71\%) had no or only mild state anxiety during the dental intervention, three participants (8\%) had moderate state anxiety, and eight participants (21\%) had a high level of state anxiety during the dental intervention. An analysis of patients' scores on the STAI state and trait scales using Spearman's Correlation test showed a positive and moderate correlation between these two scores $(p<0.001)$. These findings indicate that patients' anxiety level increased significantly during the dental intervention with an increase in the general level of anxiety; in addition, individuals with general anxiety experienced more anxiety during the dental intervention (Table 2).

A two-way repeated measures ANOVA was used for each variable as well as HR and GSR values to analyse the relationship between the GSR and HR values and the independent variables. According to the patients' MDAS scores, 24 of the participants (63.2\%) had no anxiety (MDAS<15), and 14 (36.8\%) had anxiety (MDAS $>15$ ). Although there was no statistically significant correlation between patients' MDAS scores and the change in their GSR values $(p=0.464)$, we determined a statistically significant correlation between MDAS scores and HR values $(p=0.008)$. We also found a statistically significant correlation between age and GSR values $(p=0.011$ ) However, there was no statistically significant correlation between age and HR values $(p=0.231)$. Regarding the gender of the participants, there was no statistically significant correlation between gender and GSR values ( $p=0.732$ ), but there was a statistically significant correlation between gender and $H R$ values $(p=0.002)$. According to the findings, HR changed more among women compared to men. We did not detect any statistically significant correlation between the STAI scores and the changes in GSR and HR values ( $p>0.05$ ) (Table 3).

As described above, in this study, the patientdentist interaction was divided into three sessions-presurgery, oral surgery, and post-surgery. Oral surgery

\begin{tabular}{|c|c|c|c|c|c|c|c|c|}
\hline & \multicolumn{2}{|c|}{ MDAS } & \multicolumn{3}{|c|}{ STAI state } & \multicolumn{3}{|c|}{ STAI trait } \\
\hline Score & No $(<15)$ & $\begin{array}{l}\text { Yes } \\
(>15)\end{array}$ & $\begin{array}{l}1^{\text {st }} \text { level } \\
(20-37)\end{array}$ & $\begin{array}{l}2^{\text {nd }} \text { level } \\
(38-44)\end{array}$ & $\begin{array}{l}3^{\text {rd }} \text { level } \\
(45-80)\end{array}$ & $\begin{array}{l}1^{\text {st }} \text { level } \\
(20-37)\end{array}$ & $\begin{array}{l}2^{\text {nd }} \text { level } \\
(38-44)\end{array}$ & $\begin{array}{l}3^{\text {rd }} \text { level } \\
(45-80)\end{array}$ \\
\hline Frequency (n) & 24 & 14 & 27 & 3 & 8 & 18 & 10 & 10 \\
\hline$\%$ & 63.2 & 36.8 & 71.1 & 7.9 & 21.1 & 47.4 & 26.3 & 26.3 \\
\hline
\end{tabular}


session was divided into three phase and each phase was divided into three, seven, and three sub-phases respectively. The mean values for patients during the oral surgery session are shown in Figure 2. While there was a significant difference between the GSR values in the pre-op phase $(p<0.001)$, no significant differences were found between the changes in the HR values ( $p=0.544)$. According to the paired comparison of the pre-op GSR values, there was a statistically significant correlation between unit preparation (P1) and surgeon preparation (P3) $(p<0.001)$. However, we did not determine a statistically significant correlation between P1 and surgical field preparation. We noticed that P3 was responsible for the significant difference. The last level of the pre-op phase (P3) had

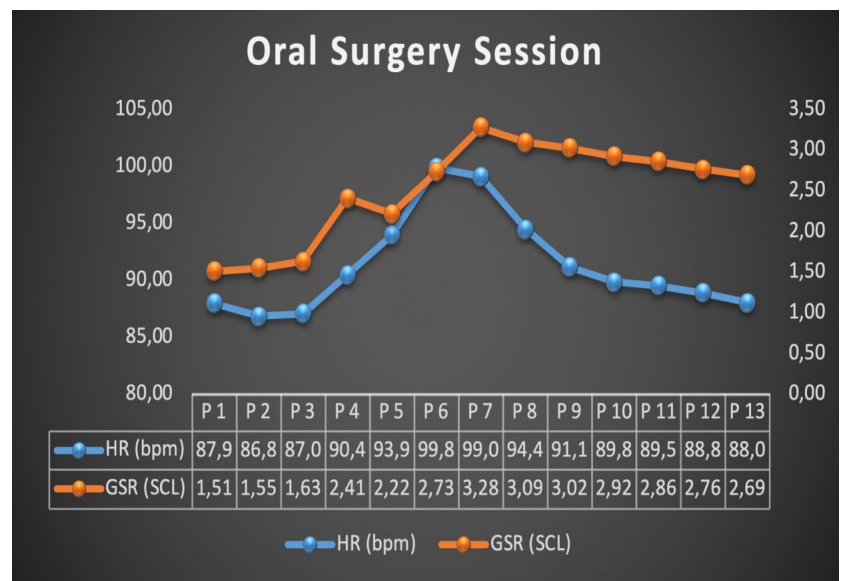

Figure 2. Mean values of the oral surgery session and the reaction of each level

GSR: Galvanic skin response, HR: Heart rate, SCL: Skin conductance level a statistically high value compared to the other levels (Figure 3).

In the op, which is the second sub-phase of the oral surgery session, the changes in the GSR and HR values were compared. According to the results of the Friedman test, there was a statistically significant difference between the mean values of op GSR and op HR $(p<0.001)$. The changes in GSR and HR values during the sub-phases of the oral surgery are presented in Figure 4.

The results of the Friedman test revealed a statistically significant difference between the postop GSR and HR values $(p<0.001)$. The surgery $(P 11)$ values were significantly higher than the end of surgery (P13) values, and there was a statistically

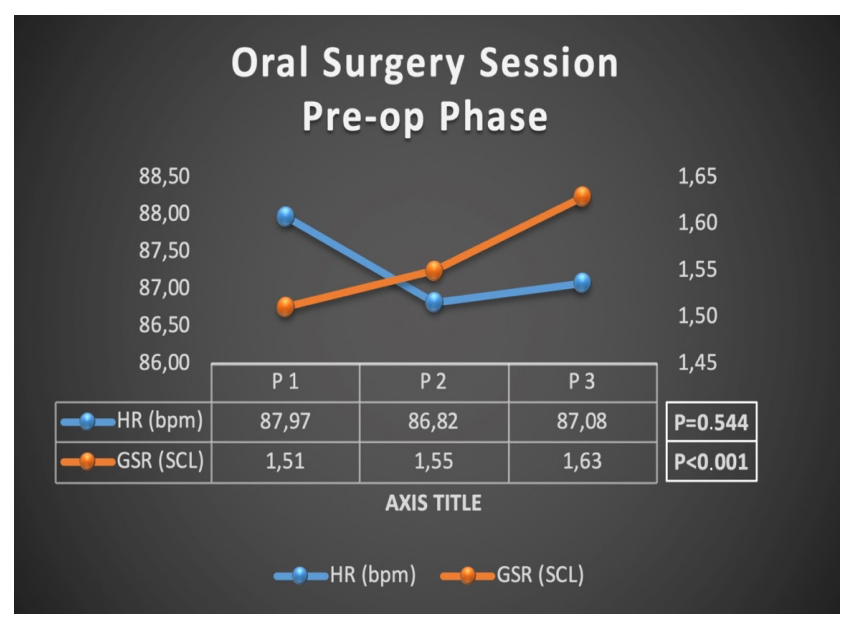

Figure 3. Mean values of the pre-operative phase of the oral surgery session and the reaction of each level

GSR: Galvanic skin response, HR: Heart rate, SCL: Skin conductance level, Pre-op phase: Pre-operative phase

\begin{tabular}{|l|l|l|l|l|l|}
\hline \multicolumn{2}{|l}{ Table 3. Tests of between-subjects effects of each parameters } & Mean square & F & p & Partial eta squared \\
\hline \multirow{3}{*}{ MDAS } & GSR & 8,560 & 0,548 & 0.464 & 0,015 \\
\cline { 2 - 6 } & HR & 11749,821 & 7,958 & 0.008 & 0,181 \\
\hline \multirow{3}{*}{ Age } & GSR & 157,266 & 4,308 & 0.011 & 0,275 \\
\cline { 2 - 6 } & HR & 7602,440 & 1,504 & 0.231 & 0,117 \\
\hline \multirow{3}{*}{ Sex } & GSR & 1,880 & 0,119 & 0.732 & 0,003 \\
\cline { 2 - 6 } & HR & 15555,460 & 11,347 & 0.002 & 0,240 \\
\hline \multirow{2}{*}{ STAI } & GSR & 36,157 & 2,538 & 0.093 & 0,127 \\
\cline { 2 - 6 } & HR & 4608,136 & 2,896 & 0.069 & 0,142 \\
\hline \multirow{2}{*}{ Educational status } & GSR & 16,624 & 1,087 & 0.379 & 0,116 \\
\cline { 2 - 6 } & HR & 625,845 & 0,331 & 0.855 & 0,039 \\
\hline STAI: State-trait anxiety inventory, MDAS: Modify Dental Anxiety scale, HR: Heart rate, GSR: Galvanic skin response
\end{tabular}


significant difference between information P11 and P13 $(p<0.001)$ (Figure 5).

\section{Discussion}

It is well known that anxiety and fear are common experienced by patients during dental treatments, and they create a disadvantageous stress for patients. Ayaz and Varol (3) reported that the concepts of anxiety and fear are often intermixed and used interchangeably; however, the meaning and content of these emotions is different. Fear is defined as a subjective emotion, which emerges as a reaction against a known danger. On the other hand, anxiety is defined as a state of concern and uneasiness in the presence of an unknown danger or threat $(2,3,18)$.

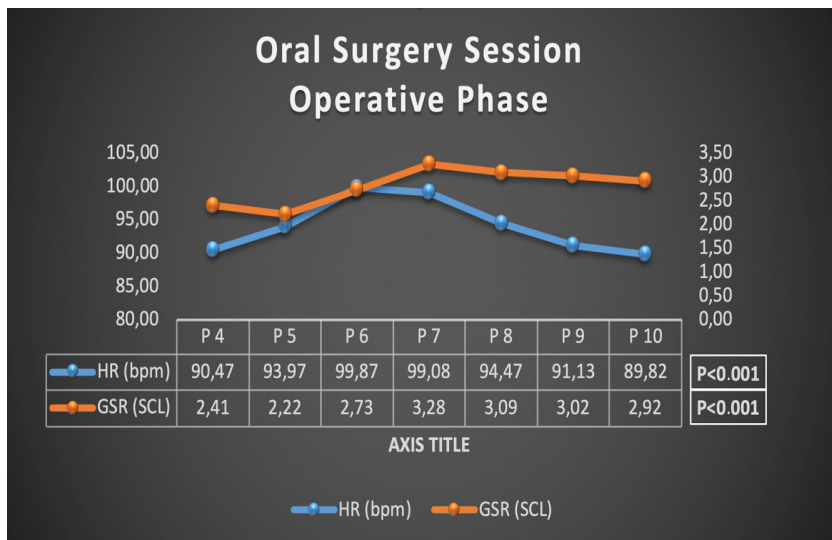

Figure 4. Mean values of the operative phase of the oral surgery session and the reaction of each level

GSR: Galvanic skin response, HR: Heart rate, SCL: Skin conductance level

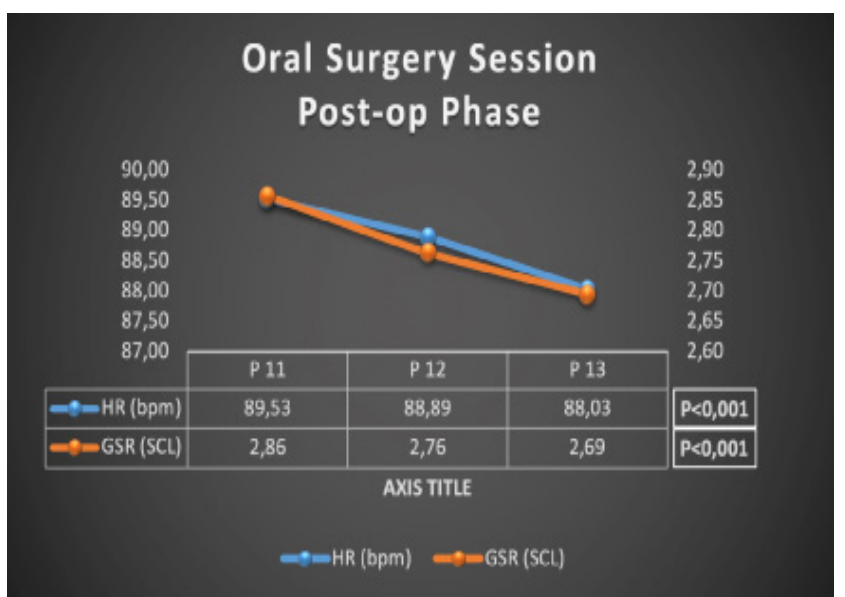

Figure 5. Mean values of the post-operative phase of the oral surgery session and the reaction of each level

GSR: Galvanic skin response, HR: Heart rate, SCL: Skin conductance level, Post-op phase: Post-operative phase
Bayındır et al. (19) defined dental anxiety as a high level of uneasiness, which develops as a result of fear and concern during the dental treatment and cannot be openly expressed. Bulut et al. (11) identified the factors that cause the emergence of anxiety, such as long and exhausting therapeutic procedures, sounds created by the equipment, previous unpleasant experiences and social experiences.

Several scales have been developed and implemented in collaborations between different disciplines to define and assess dental anxiety. Several studies focused particularly on the definition and understanding of dental anxiety $(6,7,11,20-24)$. Ay et al. (2) conducted a study to define and treat dental anxiety; they suggested that the most important factor was the necessity to focus on the cause of fear and anxiety. As a result of the individual characteristics of dental anxiety, it is important to understand the specific and individual relationship of anxiety with the distinct phases of the procedure to elucidate the definition, clinical presentation and prevention of dental anxiety.

The biometric data collection method enables the mathematical definition of anxiety levels $(25,26)$. Like other autonomous processes (e.g. body temperature, heart rhythm, blood pressure, etc.), sweating cannot be controlled consciously. Skin conductance is also affected by this autonomous sweating process and can be tracked with a GSR. The autonomous sympathetic system, which can trigger a fight-or-flight reaction depending on the stimuli, functions as an automatic warning mechanism with the help of the centres managed unconsciously by the sympathetic nervous system. Since 1972, several research articles have been published that focused on the reactions of the sympathetic nervous system, and they have recorded these reactions using the GSR method. Therefore, GSR has become one of the most reliable measurement techniques in the technical and scientific literature (27). Our emotional stimulation level changes in response to the environment. If something frightening, threatening, or amusing occurs, the emotional response increases the activity of the eccrine sweat glands. Skin conductance is not under conscious control. Instead, it is autonomously modulated by the sympathetic activity, which shapes human behaviour along with cognitive and emotional reactions. Therefore, skin conductance provides 
a direct perspective on autonomous emotional regulation (28). Research has confirmed that this reaction is related to emotional stimulation $(5,28,29)$. It should be noted that both positive ("happy" or "cheerful") and negative ("threatening" or "sad") stimuli increase excitability and skin conductance. Therefore, the GSR signal represents the intensity, not the type of emotion.

Only a few studies have focused on the implementation of GSR in dentistry. Caprara et al. (25) conducted a study on the objective measurement of dental anxiety using GSR; they reported that their objective was to determine whether the weak electric current caused by anxiety could be objectively measured. In the study, three different measurements were performed: first, a standard anxiety survey was administered; second, the galvanic skin conductance was measured; finally, false replies to three questions were recorded (25). Najafpour et al. (17) conducted a study on 151 paediatric patients and evaluated GSR measurements. They stated that GSR provided reliable and realistic data for determining dental anxiety. In their study, Casap et al. (30) investigated the effects of informed patient consent on stress levels during third molar extraction with the help of the electrodermal skin response technique.

In the present study, STAI and MDAS scales, which have up-to-date literature support, were used, and GSR was added to the study to collect biometric data. The emotions and thoughts of patients can change over the course of a dental procedure, and scales cannot always capture data with a uniform accuracy. The most significant disadvantage of the scales is their subjectivity. With the help of the objective data collected with the biometric method, the accuracy of existing anxiety scales can be tested. In this study, we had the opportunity to compare MDAS and STAI data with the biometric data. It was expected that the GSR and HR values would increase when the patient experienced continuous anxiety according to the STAI scale (STAI-2, state anxiety) and the MDAS score was above the threshold $(>15)$. We were not able to demonstrate any effect of anxiety determined with MDAS and STAI on the changes in the SCL values.

In this study, we tried to find out which emotional/ motivational changes were experienced during which stages of the dental intervention. In addition, these mood changes became distinguishable as fear, concern, or anxiety and, thus, showed how the patientdentist interaction should be during the anaesthesia and extraction and in the following stages as well as demonstrating that appropriate communication was needed. It was expected that different emotional/ motivational factors would underlie psychosomatic and anxious reactions during the key stages of the oral surgery and that these would be reflected by the biometric data.

Each phase within the three sessions of the patientdentist interaction was divided into levels according to the implemented processes. We evaluated the changes within the timeframe of each phase/level and investigated whether they affected the level of anxiety in patients. Data in the pre-op phase tended to anxiety increase gradually. This increase may be interpreted as an increase in stress as the time for the oral surgery came closer. The difference between the GSR and HR values and the elapsed time during the op confirms that the level of anxiety increased with the prolongation of the surgery, peaked at a certain time during the tooth extraction (P7), and continued at a high level; then it started to decline at the end of the surgery (P10). The decline of the anxiety level with the progress of the surgery may reflect the patient's emotions and thoughts related to the establishment of trust with the dentist, getting used to the environment, and the completion of the surgery. The decline in the GSR and HR values in the post-op session may be interpreted as the level of anxiety declining gradually after the completion of the surgery. These findings were supported by both values. The in-depth interviews confirmed these findings. It was observed that patients started to feel anxiety during the application of the anaesthesia and suffered from thoughts such as "What is going to happen to me?", and they experienced curiosity and anxiety again towards the end of the intervention.

In the pre-clinic study, the patients who did not show any significant numerical changes in the emotional/motivational variables according to the biometric data were identified, and these patients were considered to be the placebo group (15). It was reported that the psychosomatic reactions of patients could be manipulated, and the level of anxiety could be decreased with the appropriate approach to the patient on the part of the dentist (31). It was observed that the patient group which explained as placebo 
patient before was large, and that patients who demanded sedation and/or general anaesthesia could not be managed properly by clinically inexperienced surgeons; thus, the need for anaesthesia and the related risk factors increased. The psychosomatic mood changes in the placebo patients, which until now could only be diagnosed by an experienced dentist, became detectable with biometric data collection.

It was observed that certain words used by the surgeon during the operation had a negative impact on the psychosomatic state of the patients. These words, known as triggering words, may cause severe anxiety. Therefore, it was emphasized that the operation should be managed by the dentist with carefully selected communication tools.

\section{Conclusion}

It was noticed that patients' emotional/ motivational changes during the phases of the operation could be identified using the analyses of their biometric data. The simultaneous measurement of biometric parameters may, in tandem with the dentist's experience, enable the dentist to decide during the operation which procedures and approaches should be used with patients with dental anxiety. Regarding oral surgical interventions, an important step was taken toward the use of minimal surgical approaches instead of the use of additional sedation and/or general anaesthesia with the use of GSR and its components. Furthermore, we believe that this approach will also contribute to increasing patients' trust and interaction with the dentist. In future studies, the emotional/motivational findings during the stages of oral surgery can be investigated, and procedure packages based on the patient-dentist interaction can be implemented to determine a suitable surgical approach for patients with dental anxiety. Moreover, further studies are required to investigate the integration of biometric data collection devices into dental units so that dentists have the possibility of instantly using current data to adjust their approach to patients with dental anxiety.

\section{Acknowledgements}

We are thankful for the statistical analysis conducted by pharmacist Kürşat Özkan and research assistant Taner Kızılhan.

\section{Ethics}

Ethics Committee Approval: This study followed the Declaration of Helsinki regarding medical protocol and ethics, and the regional Ethical Review Board of Aydın Adnan Menderes University Faculty of Dentistry, approved the study (protocol no: ADÜDHF 2019/066, date: 17.04.2019).

Informed Consent: All patients were informed about the objective of the study and the details of the intervention, and only patients who had given their written consent were included in the study.

Peer-review: Externally peer-reviewed.

\section{Authorship Contributions}

Concept: H.O.Ş., B.A.A., Design: H.O.Ş., B.A.A., Data Collection or Processing: H.O.Ş., B.A.A., Analysis or Interpretation: H.O.Ş., B.A.A., Literature Search: H.O.Ş., B.A.A., Writing: H.O.S., B.A.A.

Conflict of Interest: No conflict of interest was declared by the authors.

Financial Disclosure: The authors declared that this study received no financial support.

\section{References}

1. Arslan S, Ertaş TE, Ülker M. The relationship between dental fear and sociodemographic variables. Erciyes Med J 2011; 33: 295300.

2. Ay $Z Y$, Çağlar $F$, Orun $B$, Uskun $E$. The consistency of the patient expressions with the surveys' results about the oral health status, dental anxiety levels and its possible determinants. Suleyman Demirel UniversityJournal of Health Sciences 2014; 5: 56-61.

3. Ayaz E, Varol G. Examination of Factors Related to Dental Anxiety Level in 1st Grade Students in Health High School of Namık Kemal University Vocational School of Health Services. Nam Kem Med J 2018; 6: 96-103.

4. Tunc EP, Firat D, Onur OD, Sar V. Reliability and validity of the modified dental anxiety scale (MDAS) in a turkish population. Community Dent Oral Epidemiol 2005; 33: 357-62.

5. Boucsein W. Principles of electrodermal phenomena. In: Electrodermal Activity. 2nd ed. Springer Science \& Business Media; 2012: 1-86.

6. Corah NL. Development of a dental anxiety scale. J Dent Res 1969; 48: 596.

7. Humphris GM, J, Freeman R, Campbell Tuutti H, D'Souza V. Further evidence for the reliability and validity of the modified dental anxiety scale. Int Dent J 2000; 50: 367-70.

8. Ilgüy D, Ilgüy $M$, Dinçer S, Bayirli G. Reliability and validity of the modified dental anxiety scale in turkish patients. J Int Med Res 2005; 33: 252-9.

9. Spielberger $C D$, Gorsuch RL, Lushene R, Vagg P, Jacobs G. Consulting psychologists press. Palo Alto, CA; 1983. 
10. Öner N, Le Compte A. Durumluk-süreklilik kaygı envanteri el kitabı. 2. Basım İstanbul: Boğaziçi Üniversitesi Yayınları; 1998.

11. Bulut E, Poyrazoğlu E, Yüksel B. Examination of dental anxiety among students of the Faculty of Dentistry of Ondokuz Mayıs University. Ondokuz Mayıs Üniversitesi Diş Hekimliği Fakültesi Dergisi 2009; 10: 16-24.

12. Jlala HA, French JL, Foxall GL, Hardman JG, Bedforth NM. Effect of preoperative multimedia information on perioperative anxiety in patients undergoing procedures under regional anaesthesia. Br J Anaesth 2010; 104: 369-74.

13. Shimmer. Shimmer GSR+ Unit. Date: 01 May 2020, Link: http:// www.shimmersensing.com/products/shimmer3-wireless-gsrsensor. 2020; http://www.shimmersensing.com/products/ shimmer3-wireless-gsr-sensor. Accessed 01 May, 2020.

14. Briggs CL. Learning how to ask: A sociolinguistic appraisal of the role of the interview in social science research. Cambridge University Press; 1986.

15. Aytekin BA, Şimşek HO. The importance of patient-doctor interaction in the context of health communication examining with the participatory action research (par) and electrodermal data collection (GSR) methods. Business \& Management Studies: An International Journal 2019; 7: 1209-24.

16. Lewin K. Field theory in social science: selected theoretical papers. Edited by dorwin cartwright; 1951.

17. Najafpour E, Asl-Aminabadi N, Nuroloyuni S, Jamali Z, Shirazi S. Can galvanic skin conductance be used as an objective indicator of children's anxiety in the dental setting? J Clin Exp Dent 2017; 9: 377-83.

18. Doğaner YÇ, Aydoğan Ü, Yeşil HÜ, Sarı O, Koç B. Dental Anxiety and Associated Factors in Young Individuals. Gulhane Med J 2015; 57: 160-4.

19. Bayındır F, Akyıl Ş, Kavrut R. The evalution of dental anxiety scale (DAS) and visual analogue scale (VAS) in the patients appling to the prosthodontics department. Atatürk Üniv Diş Hek Fak Derg 2003; 13: 34-9.

20. Kupeli I, Gülnahar Y. Comparing different music genres in decreasing dental anxiety in young adults who underwent third molar surgery in Turkey: randomized controlled trial. J Oral Maxillofac Surg 2020; 78: 546.

21. Lundgren J, Berggren U, Carlsson SG. Psychophysiological reactions in dental phobic patients during video stimulation. Eur J Oral Sci 2001; 109: 172-7.

22. Öcek ZA, Karababa AO, Türk $M$, Çiçeklioğlu $M$, Kandemir ş. Assessment of aetiology of dental anxiety of patients applying to Ege University, School of Dentistry. EÜ Diş Hek Fak Derg 2001; 22: 121-9.

23. Wolf DL, Desjardins PJ, Black PM, Francom SR, Mohanlal RW, Fleishaker JC. Anticipatory anxiety in moderately to highlyanxious oral surgery patients as a screening model for anxiolytics: evaluation of alprazolam. J Clin Psychopharmacol 2003; 23: 51-7.

24. Yamashita Y, Shimohira D, Aijima R, Mori K, Danjo A. Clinical effect of virtual reality to relieve anxiety during impacted mandibular third molar extraction under local anesthesia. J Oral Maxillofac Surg 2020; 78: 545.

25. Caprara HJ, Eleazer PD, Barfield RD, Chavers S. Objective measurement of patient's dental anxiety by galvanic skin reaction. J Endod 2003; 29: 493-6.

26. van Dooren $M$, de Vries JJ, Janssen JH. Emotional sweating across the body: comparing 16 different skin conductance measurement locations. Physiol Behav 2012; 106: 298-304.

27. Boucsein W. Electrodermal activity. In: Springer Science \& Business Media; 2012: 1-86.

28. Critchley HD. Electrodermal responses: what happens in the brain. Neuroscientist 2002; 8: 132-42.

29. Salimpoor VN, Benovoy M, Longo G, Cooperstock JR, Zatorre RJ. The rewarding aspects of music listening are related to degree of emotional arousal. PLoS One 2009; 4: 7487.

30. Casap N, Alterman M, Sharon G, Samuni Y. The effect of informed consent on stress levels associated with extraction of impacted mandibular third molars. J Oral Maxillofac Surg 2008; 66: 87881.

31. Litt MD, Nye C, Shafer D. Coping with oral surgery by self-efficacy enhancement and perceptions of control. J Dent Res 1993; 72: 1237-43. 